\title{
Trait meaning in impression formation as a function of trait variance
}

\author{
RAMADHAR SINGH \\ Indian Institute of Technology, Kanpur, India
}

\begin{abstract}
Fifty-four subjects formed an impression of a stimulus person based upon his one trait, and generated other traits possibly applicable to him. They also rated the likableness value of each of their generated adjectives. The test traits were neutral in likableness value but differed as to their variance. Frequency distribution of the generated traits with respect to their scale value produced a maximum probability function for a neutral trait of low variance and an equal probability function for a neutral trait of high variance. Implied traits thus seemed to be influenced by the variance of the test trait.
\end{abstract}

Ostrom (1972) has suggested that each personalitytrait word implies several other traits and that evaluation of a person is made on the basis of not only the test trait but also the other traits implied by it. Furthermore, the implied traits vary as a function of their own valence and that of the test trait.

Results of two word-association studies (Pollio, 1964; Staats \& Staats, 1959) and one person perception study (Podell, 1961) provide some indirect support for Ostrom's meaning shift formulation. More direct support has been found in a recent study by Davis and Ostrom (Note 1). They provided their subjects with adjectival descriptions of 20 stimulus persons and required the subjects to indicate their certainty as to the presence of some other traits in the target persons. Two lists of adjectives varying in likableness value (Anderson, 1968) were given to the subjects for this purpose. Examinations of the mean certainty ratings as a function of scale value of test sets and scale value of response traits disclosed different relationships for the non-neutral and neutral sets. With the non-neutral sets (highly likable, moderately likable, moderately dislikable, and highly dislikable), the most strongly implied response traits were of the same scale value but of greater polarity than the test traits. Dissimilar traits were also implied but with lower certainty. The overall relationship was thus linear. For the neutral traits, however, a maximum probability function was present. That is, the neutral traits were most strongly implied, and the positive and negative traits were less implied, making an inverted U-shaped function. One purpose of this study was to explicate this maximum probability function, using an entirely different kind of response

The author is grateful to Professor Thomas M. Ostrom, who sponsors this paper and takes full editorial responsibility for its content. for his valuable comments on an early version of this paper. and to Professor B. J. Winer for his helpful advice in the data analvsis. Requests for reprints should be addressed to Ramadhar Singh, Department of Humanities and Social Sciences, Indian Institute of Technology, Kanpur 208016, U. P., India. measure. It is proposed that a maximum probability function for neutral traits can also be obtained, if the subjects are asked to generate other traits possibly applicable to the target person and a frequency distribution of the generated traits is made with respect to their scale value. Such free-association responses would also allow a direct comparison of the test traits in terms of the pooled scale value of the generated associates.

The second intent of the present study was to examine the effect of trait variance on the distribution of generalized traits. In his master list of 555 personality-trait words, Anderson (1968) has reported variance of each trait in addition to its likableness value. The variance index represents between-subjects differences in the rating of a trait. A trait with high variance probably means different things to different people. It can also evoke associations of all sorts and values. If it is so, traits of all values could be generalized with equal probability to a stimulus person described by a neutral trait of high variance. Accordingly, maximum probability function and equal probability function can be expected for a neutral trait of low and high variance, respectively.

\section{METHOD}

\section{Stimuli}

From the Anderson list (1968), six traits were selected from the neutral region (2.80-3.32). Three traits (hesitant, inoffensive, and unlucky) were of low variance $(M=.73)$ and three traits (discriminating, self-righteous. and shrewd) were of high variance $(M=2.80)$. In selecting these traits as stimuli, the main consideration was to equate the test traits of the low $(M=3.01)$ with those of high $(M=2.99)$ variances in their overall likableness values. All of the six traits were written on separate cards for the experimental purpose.

\footnotetext{
Subjects

Fifty-four students from an introductory psychology course at Purdue University served as subjects. Participation in the experiment fulfilled their course requirement. For the test traits of high and low variance, they were randomly divided into two groups. The 27 subjects of each group were further divided into three
} 


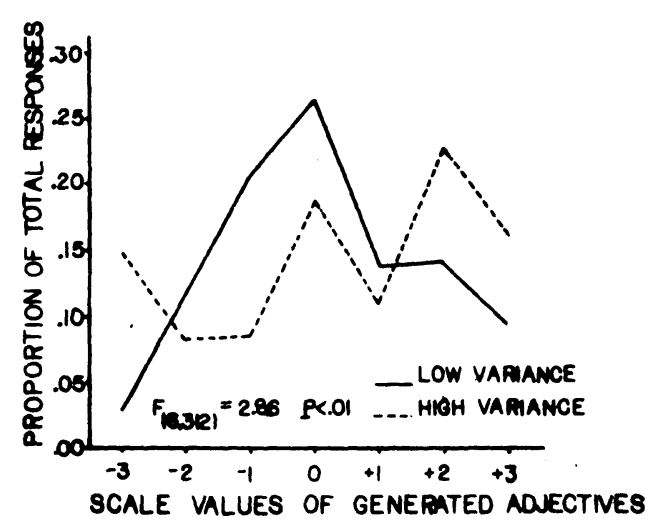

Figure 1. Mean proportion of total responses as a function of trait variance and scale values of generated adjectives. (Listed F ratio is for trait variance by scale value of generated traits effect.)

subgroups in order to have an equal number of subjects respond to each of the three traits.

\section{Procedure}

In the experimental session, subjects were run in groups of 15-20. Upon arrival, each subject received one card listing a single personality trait. They read the trait and put the card upside down. They formed an impression of the described person for $1 \mathrm{~min}$ and then wrote other traits possibly applicable to him on a separate sheet of paper. They generated traits for $3 \mathrm{~min}$ only.

As the subjects generated traits of their own choice, ratings of scale value of each of the generated traits were solicited from the same subjects. They were urged to consider each of their generated adjectives as characteristic of different persons and then to indicate how much they would like a person if a given trait were used to describe him. The likableness ratings were made on a 21-point scale, having 0 specified as neutral and -10 and +10 as limits for dislikableness and likableness, respectively. This scale was written on the black board, and the subject selected one of the 21 numbers for each of the generated traits.

\section{RESULTS}

Traits generated in response to the test trait varied in number from 4 to 20 . Mean number of associates to the traits of low $(M=10.48)$ and high $(M=10.41)$ variance were equal $(t<1)$. Analysis of the simple average of the scale value of all the attributed traits also yielded identical likableness value for the traits of low $(M=11.45)$ and high $(M=12.04)$ variance $(t<1)$. This finding is in accord with a previous result of identical evaluation of the homogeneous and hetęrogeneous neutral sets (Edwards \& Ostrom, 1971; Singh \& Byrne, 1971).

To test the predictions, the original 21-point scale was reduced to a 7 -point scale: $-3,-2,-1,0,+1,+2$, and +3 , and the proportion of the total responses in each of the seven categories was calculated for each subject separately. Proportion of the total responses was then examined as a function of trait variance (low vs. high) and scale value of the generated traits (seven levels). In this 2 by 7 between-within analysis of variance test, the effect of scale value of generated traits on the proportion of total responses was significant $(F=3.31$, df $=6 / 312, p<.003)$. For the seven levels of scale value, the mean proportion of total responses were $.094, .099, .144, .225, .124, .184$, and .128 from the negative to the positive end. These means fit very well within a maximum probability function $\left(F_{\text {quad }}=4.71, \mathrm{df}=1 / 52, \mathrm{p}<.05\right)$, supporting the first prediction.

The hypothesized trait variance by scale value of the generated traits effect was also significant $(F=2.86$, $\mathrm{df}=6 / 312, \mathrm{p}<.01$ ). Figure 1 depicts the profile of this interaction. An examination of this interaction indicated that the effect of scale value of the generated traits on the proportion of responses held only in the case of traits of low variance $(F=4.59$, $\mathrm{df}=6 / 156$, $\mathrm{p}<.001)$. Support for a maximum probability function was indeed very strong $\left(F_{\text {quad }}=19.07\right.$, $\mathrm{df}=1 / 26, \quad \mathrm{p}<.001)$. Proportion of the total responses evoked by traits of high variance, on the other hand, did not seem to be influenced by their own scale value $(F=1.93, \mathrm{df}=6 / 156$, n.s. $)$. Associates of all the seven values appeared to be equally probable in the trait-generalization process. However, there was an indication for a cubic trend $\left(F_{\text {cub }}=4.49, \mathrm{df}=1 / 26, \mathrm{p}<.05\right)$ in the distribution of responses in spite of a nonsignificant overall effect.

All the three traits of high variance (discriminating, self-righteous, and shrewd) behaved alike in trait evocation $(F<1)$. Two (inoffensive and unlucky) of the three low variance traits similarly produced parallel effects, but the trait "hesitant" engendered more positive than neutral associates. Because of this discrepancy, the trait replication by scale value of generated traits effect was present $(F=2.78$, df $=$ $12 / 144, p<.01)$ in case of low variance traits.

\section{DISCUSSION}

Findings of the present experiment are informative in two important ways. First, they establish a maximum probability function for the synonymic associates of the neutral personality traits. as was predicted. It is evident that neutral traits imply more neutral than positive and negative traits. This is highly consistent with the results of Davis and Ostrom (Note 1), who had employed completely different experimental design and response measure. Second, the results disclose a new type of distribution for the alternative interpretations given to a neutral trait of high variance. An equal probability function appears to be a better choice for the traits implied by high variance traits. This not only adds a new type of distribution to the three already mentioned by Davis and Ostrom (Note 1) but also calls attention to the utility of the trait variance parameter in the understanding of the process of personality impression formation.

It should be noted here that a cubic trend was present in the proportion of total responses made to the neutral traits of high variance. Reliability of this trend is, however, doubtful, as the overall effect of scale value of generated traits was nonsignificant.

An analysis of the simple average of likableness value of all the generated adjectives did not reveal any difference between the traits of high and low variance. This result is in harmony with the finding obtained through the use of evaluative scales (Edwards \& Ostrom. 
14-1: Singh \& Byrne, 1971). In addition. it strengthens Ostrom's (1969) thesis that the global evaluation of a test trait is the average of the likableness values conveyed by its alternative meanings. As the overall measure does not differentiate the traits of high variance from those of low variance, it would probably be judicious to use the response measure of the kind employed in this study in future work.

\section{REFERENCE NOTE}

1. Davis. D., \& Ostrom, T. M. Trait implication in impression tormation. Paper presented at the $81 \mathrm{st}$ annual meeting of the American Psychological Association. Montreal, 1973.

\section{REFERENCES}

ANDERSON. N. H. Likableness ratings of 555 personality-trait words. Journal of Personality and Social Psychology, 1968. 9. $272-2^{-9}$.
Edwards. J. D.. \& Ostrom. T. M. Cognitive structure of neutral attitudes. Journal of Experimental Social Psychology, 1971. 7. 36-47.

Ostrom. T. M. Meaning shift in the judgment of compound stimuli. Mimeographed manuscript. Ohio State University. 1969.

Osтrom. T. M. Trait meaning in impression formation. Mimeographed manuscript. Ohio State University, 1972.

Podell. J. E. A comparison of generalization and adaptation level theories of connation. Journal of Abnormal and Social Psychology. 1961, 62. 594-597.

Pollio, H. R. Some semantic relations among word-associates. American Journal of Psychology. 1964. 77. 249-256.

Singh. R.. \& Byrne. D. Cognitive certainty and affective neutrality as a function of stimulus homogeneity-heterogeneity. Psychonomic Science. 1971, 25. 207-208.

StaAts. A. W.. d Staats, C. K. Meaning and m: Correlated but separate. Psychological Reviews. 1959. 66, 136-144.

(Received for publication December 8, 1975.) 